\title{
Nonlinear Mass Transfer at the Electrodes with Reversible Homogeneous; Reactions:Taylor'sSeries and Hyperbolic Function Method
}

\author{
Lilly Clarance Mary ${ }^{1}$, Ramu Usha Rani ${ }^{2}$, Athimoolam Meena ${ }^{3}$, Lakshmanan Rajendran $^{2, *}$ \\ ${ }^{1}$ Department of Mathematics, Fatima College (Autonomous), Madurai, India. \\ ${ }^{2}$ Department of Mathematics, AMET (Deemed to be University), Kanathur, Chennai, India. \\ ${ }^{3}$ Department of Mathematics, Saraswathi Narayanan College, Madurai, Tamil Nadu, India. \\ *E-mail: raj_sms@ rediffmail.com
}

doi: $10.20964 / 2021.01 .73$

Received: 14 September 2020/ Accepted: 4 November 2020 / Published: 30 November 2020

The mathematical model for mass transfer with reversible homogeneous reactions is discussed. Estimation of mass transfer to and from electrodes for this reaction needs the analytical solution of nonlinear reaction-diffusion equations. Taylor's series method and hyperbolic function method are used to solve the system of nonlinear reaction-diffusion equations. Approximate closed-form of analytical expression of the concentration of substrate, reactant and product are derived for all values parameters. The empirical results are compared with the simulation results, and there is noticeable agreement. The effect of various parameter on aqueous carbonate-species concentration are also discussed. The current density and homogeneous equilibrium constant are also obtained.

Keywords: Mathematical Modeling; Non-linear equations; Taylor's Series Method; Hyperbolic Function Method; Steady-state.

\section{$\underline{\text { FULL TEXT }}$}

(C) 2021 The Authors. Published by ESG (www.electrochemsci.org). This article is an open access article distributed under the terms and conditions of the Creative Commons Attribution license (http://creativecommons.org/licenses/by/4.0/). 